\title{
Academic Achievement and Individual Differences in Learning Processes
}

\author{
Ronald R. Schmeck and Eddie Grove \\ Southern Illinois University
}

This study was concerned with the degree of relationship between academic achievement, as assessed by college grade-point average, and information-processing habits relevant to learning, as assessed by the scales of the Inventory of Learning Processes (ILP). The ILP scales of Synthesis-Analysis, Fact Retention, and Elaborative Processing were significantly related to GPA and scores on the American College Testing (ACT) Program Assessment. Thus, the successful student seems to process information in depth and encode it elaboratively, while simultaneously retaining the details of the original information. Unexpectedly, the Study Methods scale demonstrated a small but significant negative relationship with ACT scores. A path analysis suggested that the effects which Fact Retention and Elaborative Processing have upon GPA are mainly direct, while the effect of SynthesisAnalysis is mostly interpreted by ACT.

Recent laboratory studies in the areas of human learning and memory (e.g., Craik \& Tulving, 1975) have demonstrated that the way in which a person first processes a given piece of information plays a major role in determining the probability that the information will be remembered. Schmeck, Ribich, and Ramanaiah (1977) developed the Inventory of Learning Processes (ILP) in an attempt to assess individual differences in some of these information-processing

APPLIED PSYCHOLOGICAL MEASUREMENT Vol. 3, No. 1 Winter 1979 pp. 43-49

(๑) Copyright 1979 West Publishing Co. habits. Schmeck et al. demonstrated that the variables assessed by their instrument related to laboratory performance in a manner similar to that which had previously been reported by researchers who were experimentally manipulating the subjects' information-processing activities. The present study was designed to examine the relationships between the information-processing habits assessed by the ILP and performance in nonlaboratory, educational settings as assessed by college grade-point average (GPA) and college entrance examination scores of the American College Testing (ACT) Assessment.

The ILP contains the following four scales: Synthesis-Analysis (assessing deep, as opposed to superficial, information processing); Elaborative Processing (assessing elaborative, as opposed to verbatim, information processing); Fact Retention (assessing attention to details and specifics as opposed to generalities); and Study Methods (assessing repetitive, drill-andpractice habits of processing information). Laboratory studies employing the ILP (Ribich, 1976; Schmeck et al., 1977) have demonstrated that the Synthesis-Analysis, Elaborative Processing, and Fact Retention scales do relate to learning and memory. However, the fourth ILP scale, Study Methods, has not consistently related to performance in the laboratory. Thus, the present authors predicted that groups of 
high-achieving and low-achieving college students (above and below median GPAs and ACTs) would obtain significantly different profiles on the ILP, with high achievers scoring higher on the Synthesis-Analysis, Elaborative Processing, and Fact Retention scales but not on the Study Methods scale.

Furthermore, since the ACT can be regarded as an assessment of prior academic achievement and GPA as an assessment of current academic achievement, the authors assumed that ACT would be one of the causal determiners of GPA. Also, it was assumed that covariation between ILP scales and ACT and GPA would indicate causal relationships between informationprocessing habits and achievement. Thus, the ILP scales should be involved in both direct causal relationships with GPA and indirect causal relationships mediated by ACT. These assumptions were examined by means of path analysis procedures.

\section{Method}

\section{Subjects}

The subjects in the present study were 790 undergraduate students at a large midwestern university. The sample contained 397 females and 393 males.

\section{Materials and Procedure}

The Inventory of Learning Processes, developed by Schmeck et al. (1977) is made up of 62 true-false statements concerned with behaviors in which students might engage while learning within the academic environment. Scores for each scale consist simply of the total number of items answered in the keyed direction. The inventory contains the following four scales: Synthesis-Analysis (18 items); Study Methods (23 items); Fact Retention (7 items); Elaborative Processing (14 items). Test-retest reliabilities range from .79 to .88 .

The scales of the ILP were administered to classes drawn from the Schools of Liberal Arts,
Science, and Education. Cumulative GPA and ACT Composite scores were then obtained for these students from their university records. All GPAs included at least one year of academic work. The ACT scores were those submitted to the university at the time of the student's application for admission. Only students for whom complete information was available were included in these analyses. In order to protect the rights to privacy of subjects, the achievement data were matched to ILP scores by the university records office and returned to the authors with no identifying information.

\section{Results}

Students were divided at the median on the basis of GPA and on the basis of ACT scores. Table 1 presents the ILP means and standard deviations of the groups created in this manner. Multivariate analyses of variance demonstrated that the average ILP profiles of high and low achievers were significantly different, regardless of whether the groups were determined on the basis of GPA $[F(4,785)=23.02, p<.001]$ or on the basis of ACT scores $[F(4,785)=18.41, p<$ $.001]$. In both cases, high achievers scored significantly higher on Synthesis-Analysis, Fact Retention, and Elaborative Processing. In addition, the ACT groups were significantly different on Study Methods, but the low achievers in this case scored higher than the high achievers.

All of the zero-order correlations are presented in Table 2. This correlational analysis essentially supported the multivariate analyses described above. However, in order to provide information regarding the independence of the relationships and to examine the implications of the authors' assumptions regarding causality, path analysis procedures were applied to the data. The path analysis diagram and path coefficients (standardized regression coefficients) are presented in Figure 1. It should be recalled that it was assumed that (1) although GPA could not affect ACT scores, it is likely that ACT scores af- 
Table 1

ILP Means and Standard Deviations of High and Low Achievers Classified First on the Basis of GPA and Then on the Basis of ACT

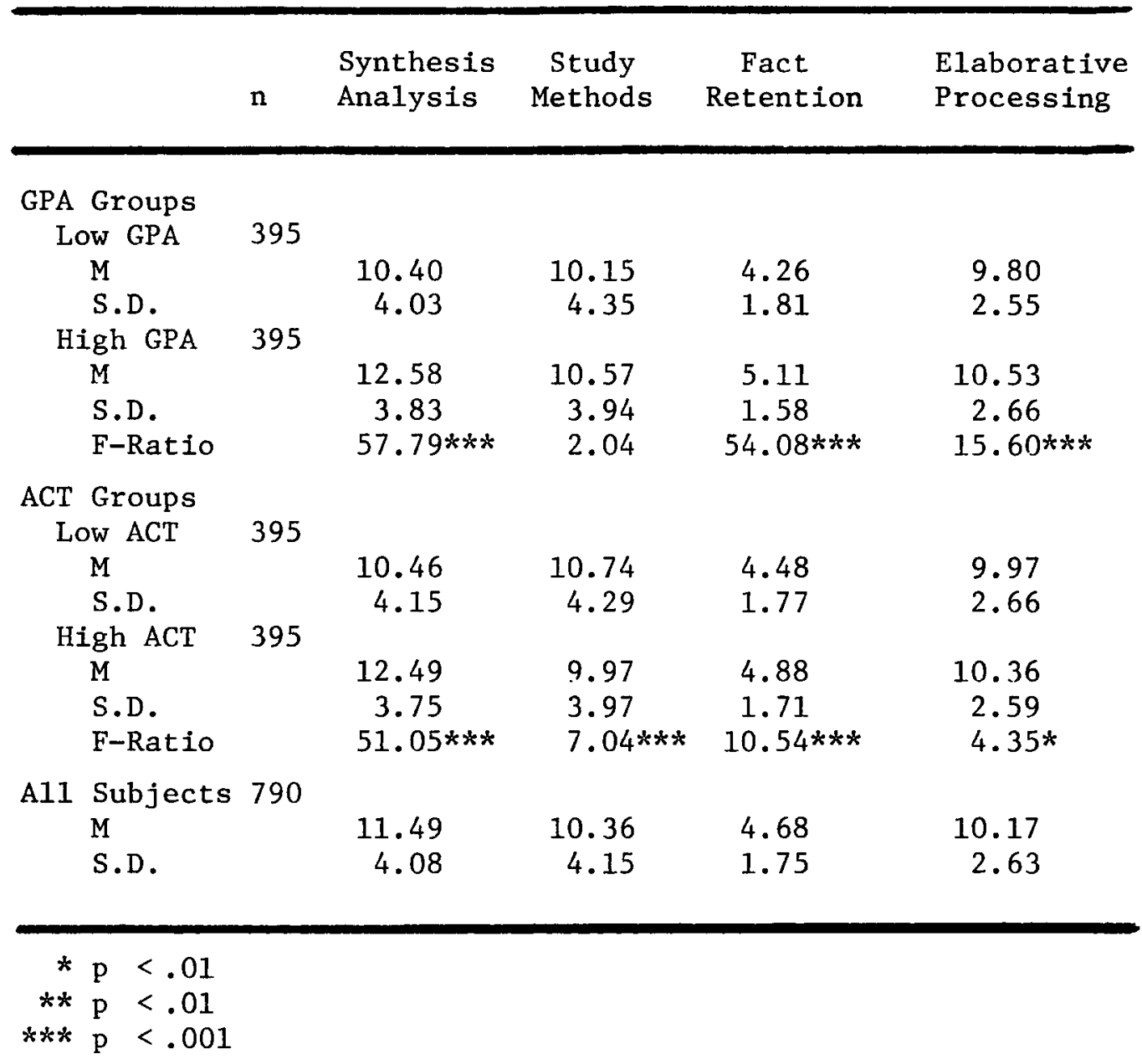

fected GPA; and that (2) ILP scales were determiners of both ACT scores and GPA.

Figure 1 has been slightly simplified by omitting the relationships among the ILP scales themselves and by deleting all statistically nonsignificant paths. This should not affect the interpretation of the diagram as it is presented. The model in Figure 1 accounted for $16 \%$ of the variance of GPA and $12 \%$ of the ACT variance. In the case of GPA, Synthesis-Analysis and Fact
Retention demonstrated the major independent relationships. If the effect coefficients are examined, it can be seen that the effects of Synthesis-Analysis $(.05+.32 \times .32=.15)$ and Fact Retention $(.13+.06 \times .32=.15)$ are equivalent (i.e., if either is changed by one standard deviation unit, the accompanying change on GPA would be about .15). However, while the effect of Fact Retention on GPA was mainly direct, the effect of Synthesis-Analysis was mostly inter- 
Table 2

Intercorrelations Among the Achievement Measures and the Scales of the ILP

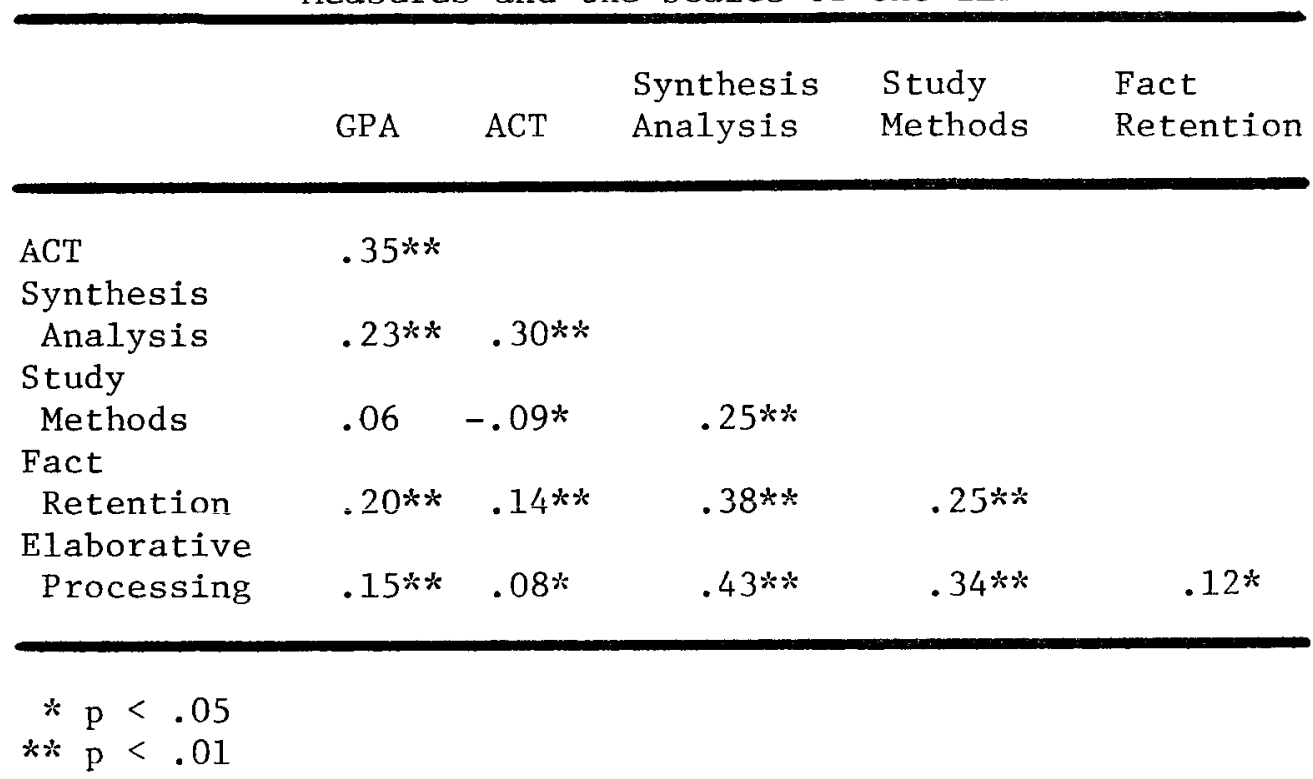

preted by ACT. Elaborative Processing also had a small but significant direct effect on GPA. In , the case of Study Methods, it should be noted that although the path diagram indicates an indirect relationship between Study Methods and GPA, there was no significant zero-order correlation (Table 2) between Study Methods and GPA; this indirect relationship with GPA would thus appear to be spurious.

\section{Discussion}

As expected, the ILP scales of SynthesisAnalysis, Fact Retention, and Elaborative Processing were significantly related to GPA and ACT scores. Unexpectedly, the Study Methods scale demonstrated a small but significant negative relationship with ACT. Path analysis suggested that the effects which Fact Retention and Elaborative Processing had upon GPA were mainly direct, while the effect of Synthesis-Analysis was mostly interpreted by ACT.
The ILP scales were originally developed by Schmeck et al. (1977) through the factor analysis of student responses to statements concerning information-processing activities used within educational settings. Schmeck et al. (1977) concluded that the scale which they labelled "Synthesis-Analysis" was assessing a dimension comparable to Craik's (1977) depth (or level) of processing. Craik states that "preliminary or shallow analyses are concerned with physical aspects of the stimulus, whereas subsequent, deeper analyses are concerned more with meanings and associative relationships" (1977, p. 680). Research employing the ILP has shown that scores on the Synthesis-Analysis scale are related positively to prose and verbal learning, note-taking efficiency, critical thinking ability, and achievement motivation, while relating negatively to anxiety (Ribich, 1976; Schmeck \& Ribich, 1978; Schmeck et al., 1977).

The present study suggests that "deep" processing is conducive to effective performance 
Figure 1

Path Analysis Diagram and Path Coefficients

(Standardized Regression Coefficients) with

Nonsignificant Paths Deleted

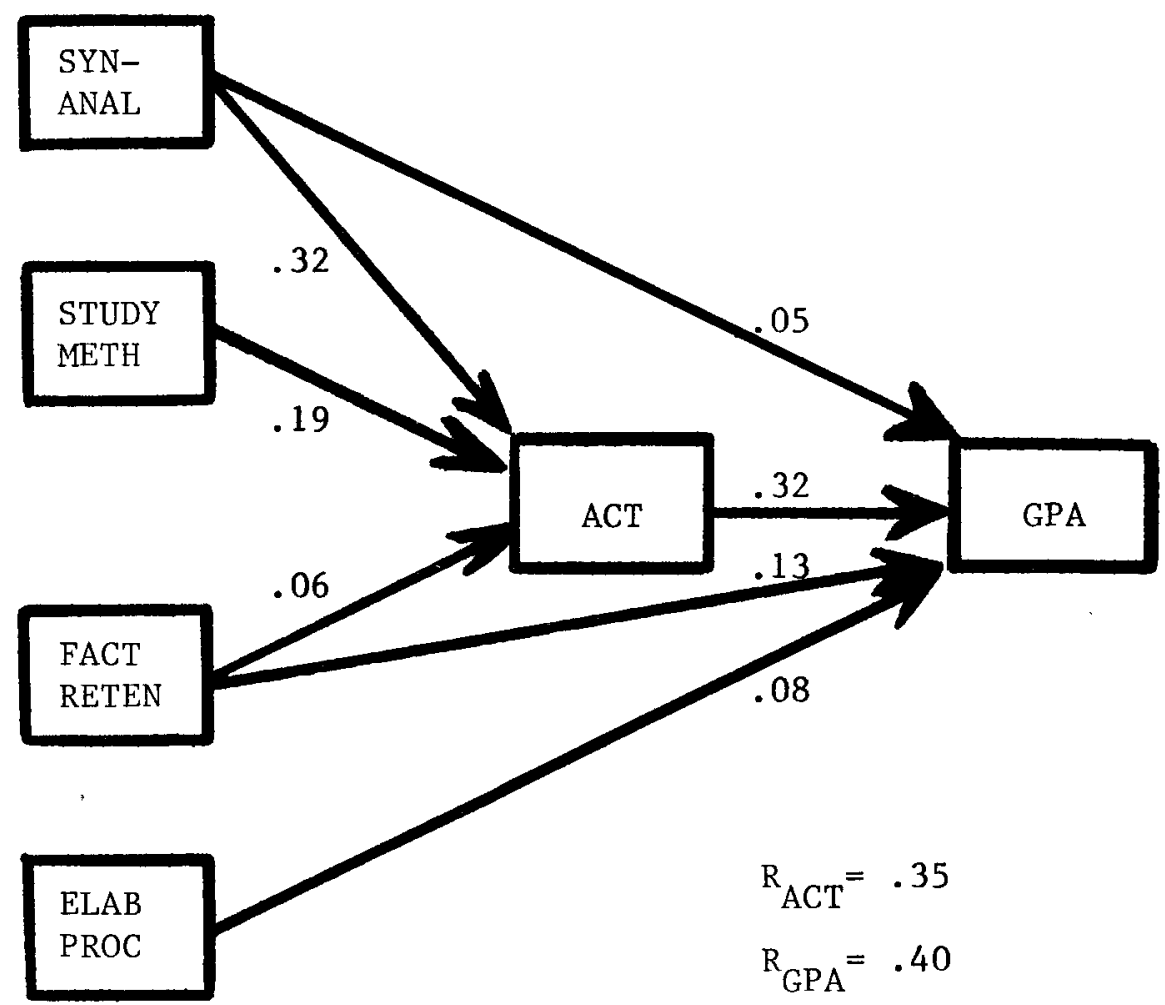

within the educational setting just as it is within the verbal learning and memory laboratory. This conclusion is supported by the work of Marton and Saljo (1976), who analyzed the content of students' answers to test questions and conducted interviews designed to determine how the students went about learning. The authors concluded that the most salient difference between students is in terms of their habitual level of processing. Path analysis of the data from the present study suggested that Synthesis-Analysis operates upon academic performance over the long term, having little effect upon performance in college independent of that caused indirectly through its effect upon prior achievement in high school.
Since the relationship between SynthesisAnalysis and achievement suggests that the successful student is attentive to higher level ideas, it might be suspected that such a student would pay less attention to concrete specifics. However, the positive relationship between Fact Retention and achievement indicates that the superior student does not attend to higher level ideas to the exclusion of specifics and details. Rather, such a student also pays more attention to details. It may be the case, as Ausubel (1968) suggests, that details must be subsumed under higher level ideas; and since the achieving college student has a more organized set of higher level ideas (i.e., more "subsumers," as indicated by high scores on Synthesis-Analysis), he or she is thus 
able to efficiently catalogue and retain more details.

The ILP's Elaborative Processing scale assesses the extent to which an individual is willing to translate new information into personal mediators, images, and examples and to fit it into a personal organizational framework. The dimension assessed by the scale appears similar to Craik's (1977) concept of elaboration of encoding, which refers to the richer (i.e., more complex, more extensive) information processing that can occur at any given level of processing. Craik and Lockhart (1972) contrasted this elaborative type of processing, which they called Type II rehearsal, with Type I rehearsal, which is the type of repetition that leads to rote memorization. Prior research has shown that scores on the Elaborative Processing scale are positively related to lecture learning, verbal learning, subjective organization, and imagery ability (Ribich, 1976; Schmeck \& Ribich, 1978; Schmeck et al., 1977). The present study also suggests that Elaborative Processing has a small but significant direct effect upon performance in the nonlaboratory educational setting.

Students earning high scores on the ILP's Study Methods scale study a great deal, but their studying tends to be of the drill and practice variety rather than the thoughtful, analytic variety of study. Research (Schmeck \& Ribich, 1978; Schmeck et al., 1977) indicates that those who score high on the scale are compliant, industrious, moderate, quiet, high on academic curiosity, and low on critical thinking ability. Such students are intent upon learning, but as Craik and Tulving (1975) have noted, intent to learn is not always a sufficient, nor (for that matter) even a necessary, condition for the occurrence of learning. The important question is, "What does the subject do with the information?" The present study suggests that individuals who earn high scores on SynthesisAnalysis and Elaborative Processing (i.e., those who encode "deeply" and "richly") can earn high GPAs, even if they earn low scores on the Study Methods scale.
The authors are aware of at least two study procedures which would force students to engage in a process very similar to that assessed by the Synthesis-Analysis scale of the ILP (Malin \& Malin, 1976; Meyer, 1975). These study procedures involve the construction of diagrams which summarize the ideas within a passage, forcing the students to abstract and label the basic ideas and diagram the interrelationships among them. These procedures might be combined with one by Weinstein $(1975,1977)$ in order to yield an even more powerful study technique. Weinstein's method requires students to elaborate upon the information in a manner similar to that assessed by the fourth ILP scale, i.e., Elaborative Processing.

\section{References}

Ausubel, D. P. Educational psychology: A cognitive view. New York: Holt, Rinehart, \& Winston, 1968.

Craik, F. I. M. Depth of processing in recall and recognition. In S. Dornic (Ed.), Attention and performance (Vol. 6). Hillsdale, NJ: Lawrence Erlbaum, 1977.

Craik, F. I. M., \& Lockhart, R. S. Levels of processing: A framework for memory research. Journal of Verbal Learning and Verbal Behavior, 1972, $11.671-684$.

Craik, F. I. M., \& Tulving, E. Depth of processing and retention of words in episodic memory. Journal of Experimental Psychology: General, 1975, 104, 268-294.

Malin, J. T., \& Malin, D. H. Text comprehension and study skills: Final report. Unpublished manuscript, University of Houston, 1976.

Marton, F., \& Saljo, R. On qualitative differences in learning: I. Outcome and process. British Journal of Educational Psychology, 1976, 46, 4-11.

Meyer, B. The organization of prose and its effects on memory. Amsterdam: North-Holland, 1975.

Ribich, F. D. Performance on word list and prose learning tasks as a function of learning style. Master's thesis, Southern Illinois University, 1976.

Schmeck, R. R., Ribich, R., \& Ramanaiah, N. Development of a self-report inventory for assessing individual differences in learning processes. Applied Psychological Measurement, 1977, 1, 413-431. 
Schmeck, R. R., \& Ribich, F. D. Construct validation of the Inventory of Learning Processes. Applied Psychological Measurement, 1978, 2, 551-562.

Weinstein, C. E. Learning of elaboration strategies. Unpublished doctoral dissertation, University of Texas at Austin, 1975.

Weinstein, C. E. Cognitive elaboration learning strategies. Paper presented at the Annual Meeting of the American Educational Research Association, Toronto, 1977.

\section{Acknowledgments}

This research was supported by Grant No. 2-10794 from the Southern Illinois University Office of Research Development and Administration.

\section{Author's Address}

Ronald Ray Schmeck, Department of Psychology, Southern Illinois University, Carbondale, IL 62901. 